\title{
Computational analysis of hygrothermal performance of renovation renders
}

\author{
J. Kočí ${ }^{1}$, V. Kočí ${ }^{1}$, J. Maděra ${ }^{1}$, P. Rovnaníková ${ }^{2} \&$ R. Černý ${ }^{1}$ \\ ${ }^{I}$ Department of Materials Engineering and Chemistry, Faculty of Civil \\ Engineering, Czech Technical University in Prague, Czech Republic \\ ${ }^{2}$ Institute of Chemistry, Faculty of Civil Engineering, \\ Brno University of Technology, Czech Republic
}

\begin{abstract}
A combined computational-experimental approach for service life estimate of surface layers of historical building made from renovation renders is presented in the paper. The experimental part is aimed at estimation of the durability of two commercial systems of double layered renovation renders in terms of their frost resistance. The computational part includes calculation of number of freeze-thaw cycles that may occur in surface layers during a reference year. To achieve this, a diffusion-type model of coupled heat and moisture transport is used. The computations are performed on historical load-bearing structure made of sandstone, brick or arenaceous marl, finished by two different hydrophobic renovation render systems.
\end{abstract}

Keywords: service life estimate, renovation renders, heat and moisture transport, experimental analysis.

\section{Introduction}

In the current practice of reconstruction of surface layers of historical buildings it is necessary to take into account some aspects, which are mostly controlled by monument care authorities. In the first place the proper material must be chosen, which is convenient according to authority's rules. The second is preserving of the original treatments and compound formulas. The choice of materials for reconstruction is then more or less ruled by supervisory authorities, which mostly choose such material that was suitable at an application on some other building before. The durability of new surface layers made of renovation renders 
is mostly estimated on the basis of experience, because too few parameters are known for reliable durability estimation. However, the choice of proper material for renovation render should be made with respect to material of load-bearing structure and suitable regarding to moisture and salt content in the masonry.

As it has been proven in $[1,2]$ a proper material configuration of building envelope may significantly extend its service life. Combination of improperly chosen materials can lead to damage caused by moisture circulation through the interface between materials [3].

Whereas most published papers are based on experimental techniques only, in this paper we bring a new technique consisting in combination of computational and experimental approach. Such approach is aimed at the determination of the number of freeze-thaw cycles in the surface layers of historical building made of renovation renders. In addition, the computational code involves the effect of hysteresis of moisture transport and storage parameters, which bring the computations near to reality. With knowledge of the yearly number of freezethaw cycles in the surface layers we can determine the service life of renovation renders by comparing with laboratory experiments.

Prediction of moisture and temperature fields in a building envelope parts of historical buildings in sufficiently long time makes possible not only a reliable analysis of durability of surface layers on the basis of a sufficient amount of input parameters but also design of the time schedule of repeated repairs. It can also offer to the supervisory authorities alternative solutions of surface layers taking into account their durability and financial demand.

\section{Description of investigated building envelope}

The studied envelope consisted of load-bearing structure and double layered renovation render (levelling and surface coat) on the exterior side and surface coat only on the interior side. Three different kinds of materials were considered - ceramic brick, sandstone and arenaceous marl - together with two different commercial systems of renovation renders. This presents six different variations of building envelope in total.

The thickness of load-bearing structure was $600 \mathrm{~mm}$ for all materials; the thickness of renovation render was $10+10 \mathrm{~mm}$ for the first system of renovation render $(\mathrm{LC} 1+\mathrm{SC} 1)$ and $10+20 \mathrm{~mm}$ for the second system of renovation render (LC2 + SC2). Material combination with investigated points is shown on Figure 1. The point $A$ is in surface coat, $2 \mathrm{~mm}$ from exterior; point $\mathrm{B}$ in levelling coat, 2 $\mathrm{mm}$ from surface coat; point $\mathrm{C}$ in load-bearing structure, $2 \mathrm{~mm}$ from levelling coat.

\section{Experimental}

In the experimental work, the frost resistance of chosen plasters was investigated under laboratory conditions. The specimen had dimensions of 40/40/160 mm. After removal from the moulds they were placed into open boxes and humidified 

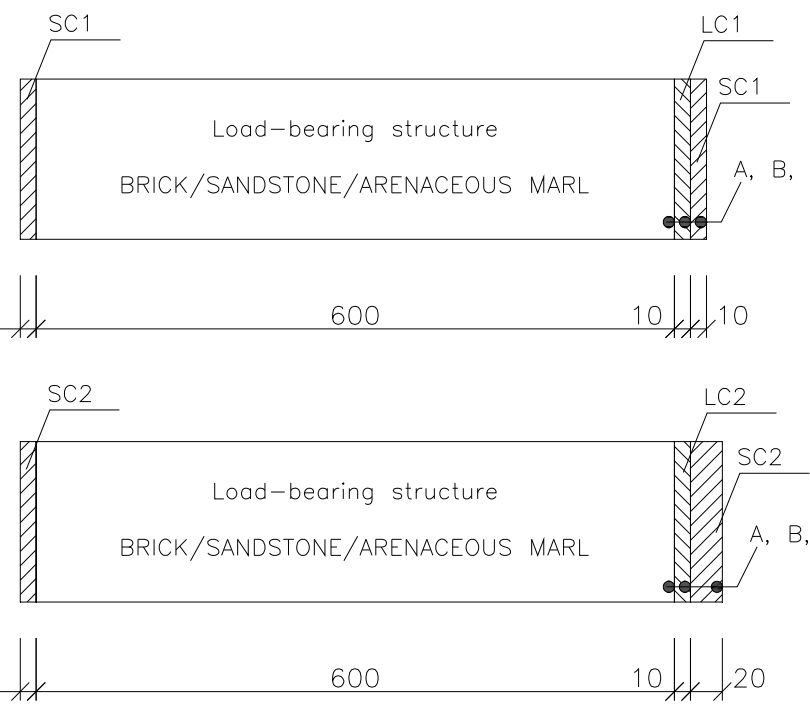

Figure 1: $\quad$ Scheme of studied building envelope.

once per day until the end of the 28-day curing period. Temperature in the laboratory was $21 \pm 1^{\circ} \mathrm{C}$, relative humidity was $45 \pm 5 \%$.

In order to measure freeze-thaw resistance of renovation renders, the water saturated testing specimens were cyclically frosted and defrosted until their damage got apparent. Three testing specimens of every coat were put into drinking water of $20 \pm 1^{\circ} \mathrm{C}$ until their full saturation. After that, the specimens were removed from water and then they were wiped by paper towel and put into

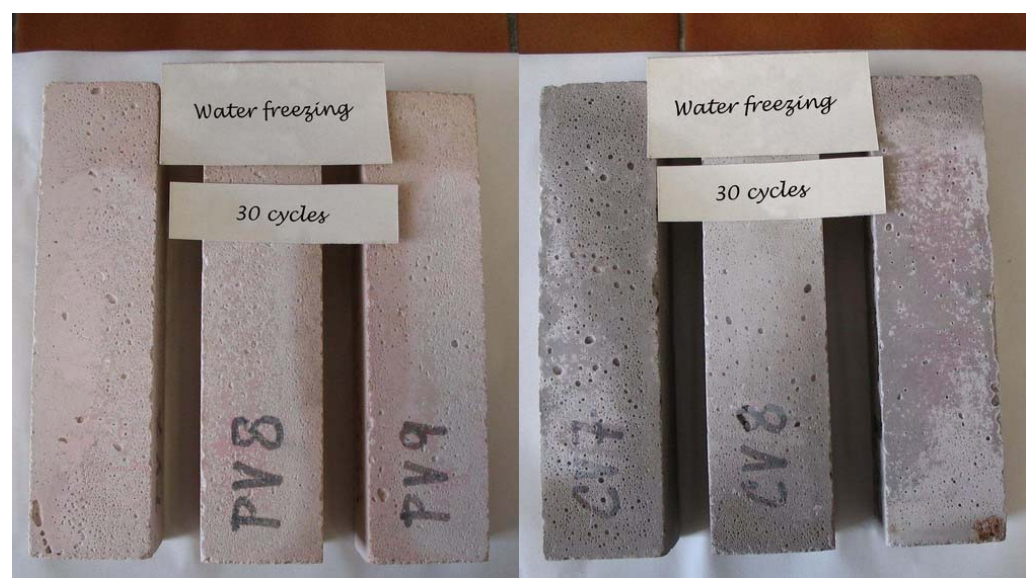

Figure 2: Different surface coats after 30 freeze-thaw cycles $\left(\mathrm{SC}_{1}\right.$ on the left, $\mathrm{SC}_{2}$ on the right). 
plastic bag. Packed specimens were put into freezing box for 6 hours. After removal, the specimens were kept in laboratory with temperature of $20 \pm 1^{\circ} \mathrm{C}$ for 2 hours, and then were put into water for 16 hours. This cycle was repeated until the visible damage of specimens. The picture of surface coats after 30 freezethaw cycles is shown in Figure 2. There is apparent a little surface destruction of both coats, but the surface still seems to be compact. The overall freeze-thaw durability is shown in Table 1 .

Table 1: Number of freeze-thaw cycles causing apparent damage of renovation renders.

\begin{tabular}{|l|c|c|c|c|}
\hline & $\mathrm{LC}_{1}$ & $\mathrm{SC}_{1}$ & $\mathrm{LC}_{2}$ & $\mathrm{SC}_{2}$ \\
\hline \hline Number of freeze-thaw cycles & 35 & $50+$ & $50+$ & 46 \\
\hline
\end{tabular}

\section{Computational}

\subsection{Input parameters}

Basic material parameters of used materials are shown in Tables 2, 3. We used the following symbols: $\rho$ - bulk density $\left[\mathrm{kg} / \mathrm{m}^{3}\right], \psi-$ porosity $[\%], \mu-$ water vapour diffusion resistance factor $[-], w_{\text {hyg }}-$ hygroscopic moisture content by volume $\left[\mathrm{m}^{3} / \mathrm{m}^{3}\right], \kappa-$ moisture diffusivity $\left[\mathrm{m}^{2} / \mathrm{s}\right], c-$ specific heat capacity $[\mathrm{J} / \mathrm{kgK}], \lambda_{\text {dry }}$ - thermal conductivity in dry conditions $[\mathrm{W} / \mathrm{mK}], \lambda_{\text {sat }}-$ thermal conductivity in water saturated conditions $[\mathrm{W} / \mathrm{mK}]$. All these parameters were measured in Laboratory of Transport Processes of the Department of Materials Engineering and Chemistry, Faculty of Civil Engineering, Czech Technical University in Prague by E. Vejmelková, M. Pavlíková and Z. Pavlík.

The sorption and desorption isotherms of studied coats of renovation render systems are shown in Figure 3.

Table 2: $\quad$ Material parameters of renovation renders.

\begin{tabular}{|l|c|c|c|c|}
\hline & $\mathrm{LC}_{1}$ & $\mathrm{SC}_{1}$ & $\mathrm{LC}_{2}$ & $\mathrm{SC}_{2}$ \\
\hline \hline$\rho\left[\mathrm{kg} / \mathrm{m}^{3}\right]$ & 1671 & 1251 & 1236 & 1199 \\
\hline$\Psi[\%]$ & 37.5 & 52.0 & 51.8 & 52.1 \\
\hline$c_{\text {dry }}[\mathrm{J} / \mathrm{kgK}]$ & 562 & 592 & 1156 & 1192 \\
\hline$c_{\text {sat }}[\mathrm{J} / \mathrm{kgK}]$ & 822 & 908 & 1763 & 1735 \\
\hline$\mu_{\text {dry cup }}[-]$ & 19 & 27 & 28 & 20 \\
\hline$\mu_{\text {wet cup }}[-]$ & 7.114 & 9.251 & 6.220 & 5.018 \\
\hline$\lambda_{\text {dry }}[\mathrm{W} / \mathrm{mK}]$ & 0.481 & 0.532 & 0.409 & 0.384 \\
\hline$\lambda_{\text {sat }}[\mathrm{W} / \mathrm{mK}]$ & 1.037 & 1.165 & 0.973 & 0.576 \\
\hline$w_{\text {hvg }}\left[\mathrm{m}^{3} / \mathrm{m}^{3}\right]$ & 0.0233 & 0.0358 & 0.0334 & 0.0312 \\
\hline
\end{tabular}


Table 3: $\quad$ Material parameters of load-bearing structure.

\begin{tabular}{|l|c|c|c|}
\hline & Brick & Sandstone & $\begin{array}{c}\text { Arenaceus } \\
\text { marl }\end{array}$ \\
\hline \hline$\rho\left[\mathrm{kg} / \mathrm{m}^{3}\right]$ & 1670 & 1809 & 1400 \\
\hline$\psi[\%]$ & 37.5 & 31.0 & 63.1 \\
\hline$c[\mathrm{~J} / \mathrm{kgK}]$ & 1202 & 850 & 837 \\
\hline$\mu[-]$ & 19.5 & 7.5 & 5.0 \\
\hline$\lambda_{\mathrm{dry}}[\mathrm{W} / \mathrm{mK}]$ & 0.500 & 1.100 & 0.710 \\
\hline$\lambda_{\text {sat }}[\mathrm{W} / \mathrm{mK}]$ & 0.648 & 3.650 & 0.890 \\
\hline$\kappa\left[\mathrm{m}^{2} / \mathrm{s}\right]$ & $2.65 \cdot 10^{-7}$ & $2.5 \cdot 10^{-6}$ & $1.0 \cdot 10^{-8}$ \\
\hline$w_{\text {hyg }}\left[\mathrm{m}^{3} / \mathrm{m}^{3}\right]$ & 0.0480 & 0.00567 & 0.01 \\
\hline
\end{tabular}

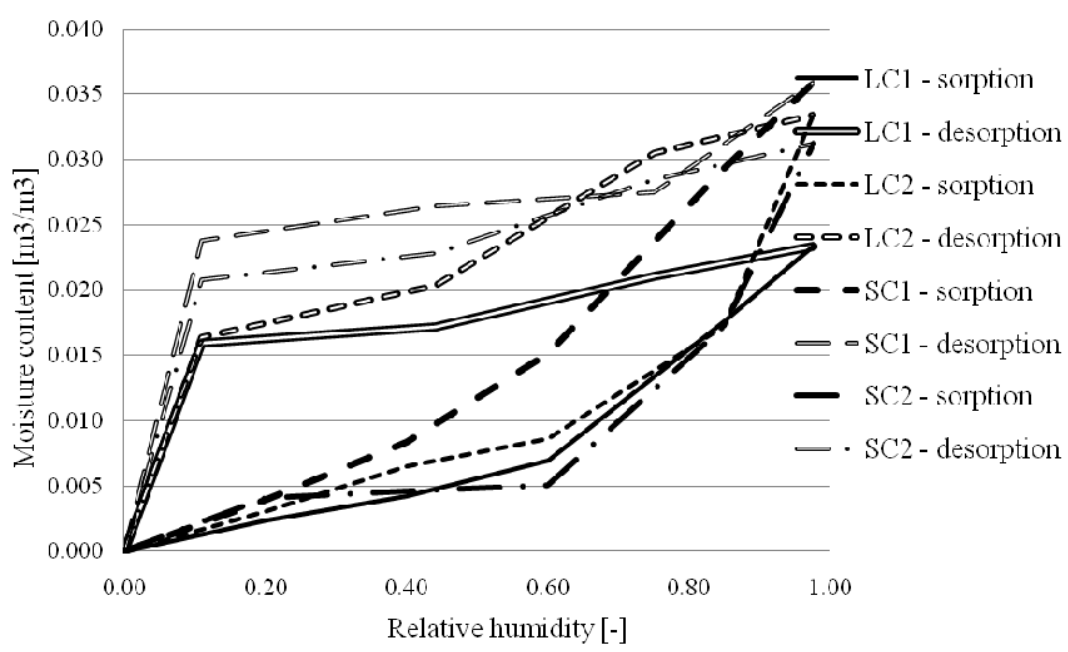

Figure 3: Sorption and desorption isotherms of studied coats of renovation render systems.

In Figure 4 we present the moisture diffusivity of studied coats, which were obtained for sorption phase only. Contrary to the sorption isotherms, where desorption curves can be obtained by common experimental techniques, the desorption curve of moisture diffusivity had to be set empirically as for its experimental determination no quite reliable techniques are available at present. Based on the results of experiments and computational analyses described in [4], it was estimated to be one order of magnitude lower than the adsorption curve.

As boundary conditions in the exterior were used climatic data for Prague in the form of Test Reference Year (TRY), which contains hourly values of average climatic data for 30 years. On the interior side were used constant values of relative humidity and temperature, $55 \%$ and $21{ }^{\circ} \mathrm{C}$, respectively. The simulation was started for $1^{\text {st }}$ June and was done for 5 years. 


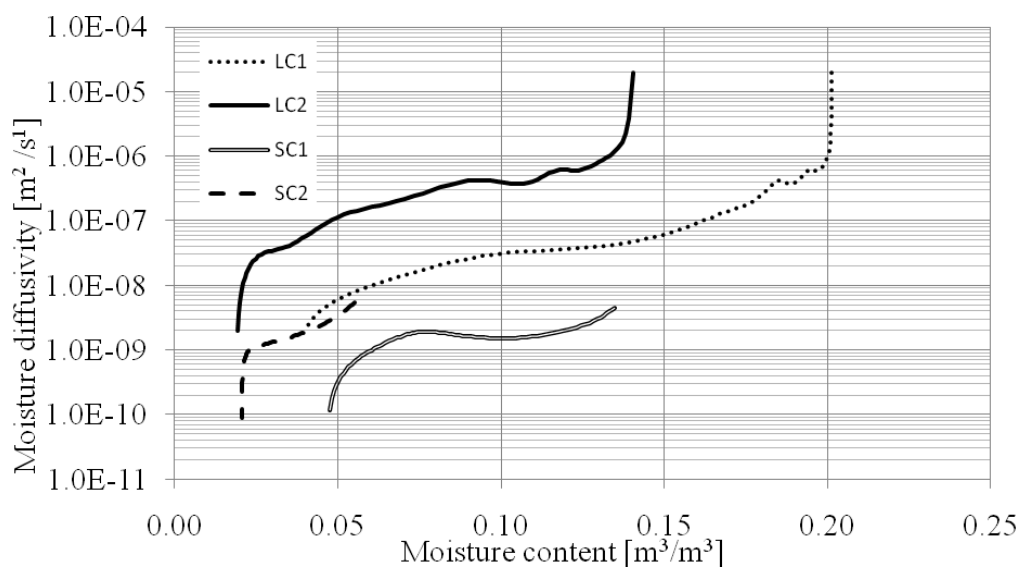

Figure 4: Moisture diffusivity of studied coats of renovation render systems.

\subsection{Computational model}

All computations were accomplished by the computational program Transmat 7.1 [5], which was developed at Department of Materials Engineering and Chemistry, Faculty of Civil Engineering, Czech Technical University in Prague on the basis of general finite elements package SIFEL [6]. The partial differential equations of coupled transport of heat and moisture which are formulated according to a chosen model are solved by finite element method. In the particular case in this paper, Künzel's model was used [7],

$$
\begin{gathered}
\frac{d \rho_{v}}{d \varphi} \frac{\partial \varphi}{\partial t}=\operatorname{div}\left[D_{\varphi} \operatorname{grad} \varphi+\delta_{p} \operatorname{grad}\left(\varphi p_{s}\right)\right] \\
\frac{d H}{d T} \frac{\partial T}{\partial t}=\operatorname{div}(\lambda \operatorname{grad} T)+L_{v} \operatorname{div}\left[\delta_{p} \operatorname{grad}\left(\varphi p_{s}\right)\right]
\end{gathered}
$$

where $\rho_{v}$ the partial density of moisture, $\varphi$ relative humidity, $\delta_{p}$ permeability of water vapour, $p_{s}$ partial pressure of saturated water vapour, $H$ enthalpy density, $L_{v}$ heat of evaporation, $\lambda$ thermal conductivity, $T$ temperature,

$$
D_{\varphi}=D_{w} \frac{d \rho_{v}}{d \varphi}
$$

is liquid moisture diffusivity coefficient, $D_{w}$ capillary transport coefficient.

For describing the path between the adsorption and desorption isotherms an empirical procedure was chosen which follows Pedersen's hysteretic model [8],

$$
\xi=\frac{a_{d}\left(w_{p}-w_{a}\right)^{2} \xi_{d}+a_{a}\left(w_{p}-w_{d}\right)^{2} \xi_{a}}{\left(w_{d}-w_{a}\right)^{2}},
$$


where $w_{p}$ is the value of moisture content from previous calculation step, $w_{a}$ and $w_{d}$ are values of moisture content for adsorption and desorption cycles, $\xi_{a}$ and $\xi_{d}$ the values of tangent adsorption and desorption in the points $w_{a}$ and $w_{d}, a_{a}$ and $a_{d}$ the correction coefficients.

For describing the path between adsorption and desorption phase of moisture diffusivity, a modification was needed in order to express the hysteretic effect in more accurate way (see [9] for more details).

\subsection{Results of computational simulations}

Results of computational simulations are presented depending on material of load-bearing structure. The results are drawn only for point $\mathrm{A}$, which presents output in surface coats $\left(\mathrm{SC}_{1}\right.$ and $\left.\mathrm{SC}_{2}\right), 2 \mathrm{~mm}$ from exterior side. The outputs from other points (B and $\mathrm{C}$ ) were not given because mostly there did not occur any freeze-thaw cycles. In each figure there are drawn time behaviour of temperature and moisture content together with level of hygroscopic moisture content and freezing point of water.

\subsubsection{Load-bearing structure made of brick}

By analyzing output data in Fig. 5 quite significant differences were found between $\mathrm{SC}_{1}$ and $\mathrm{SC}_{2}$. While $\mathrm{SC}_{1}$ exhibited 2 freeze-thaw cycles with average duration of 4 hours, for SC2 it was 8 cycles with average duration of 8.75 hours.
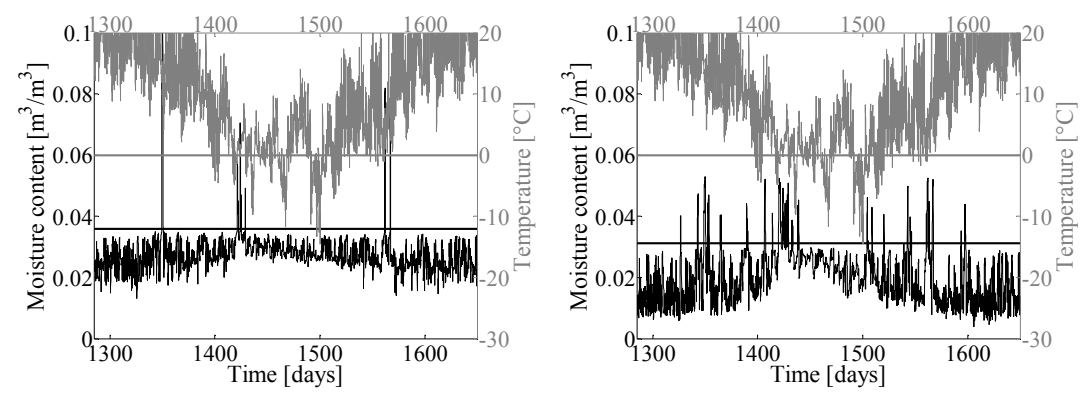

Figure 5: Time behaviour of temperature and moisture content in surface coats on load-bearing structure made of brick; $\mathrm{SC}_{1}$ on the left, $\mathrm{SC}_{2}$ on the right.

\subsubsection{Load-bearing structure made of sandstone}

In case of load-bearing structure made of sandstone, the difference in number of freeze-thaw cycles between $\mathrm{SC}_{1}$ and $\mathrm{SC}_{2}$ was significant as well. The $\mathrm{SC}_{1}$ showed only one cycle with duration of 2 hours during whole reference year, whereas $\mathrm{SC}_{2}$ showed 6 cycles in total, with average duration of 10.5 hours. 

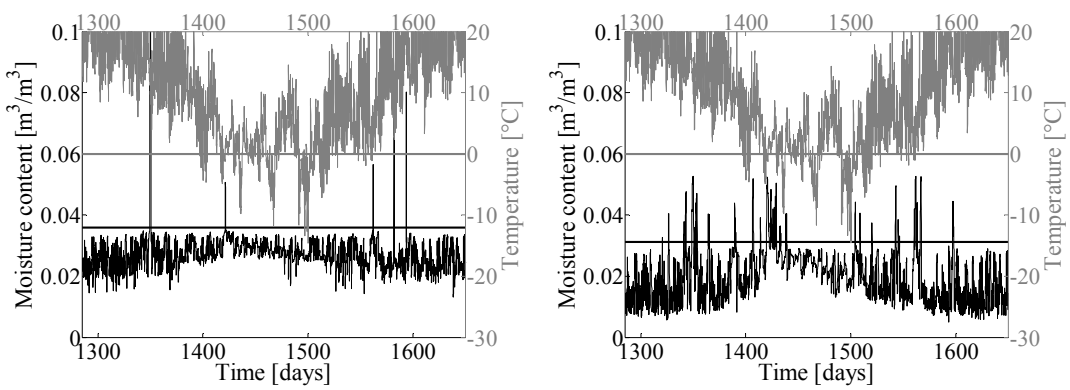

Figure 6: Time behaviour of temperature and moisture content in surface coats on load-bearing structure made of sandstone; $\mathrm{SC}_{1}$ on the left, $\mathrm{SC}_{2}$ on the right.

\subsubsection{Load-bearing structure made of arenaceous marl}

Best computational results were achieved for building envelope with loadbearing structure made of arenaceous marl. $\mathrm{SC}_{1}$ was without any freeze-thaw cycle during whole reference year. $\mathrm{SC}_{2}$ exhibited 6 cycles with average duration of 9.3 hours.
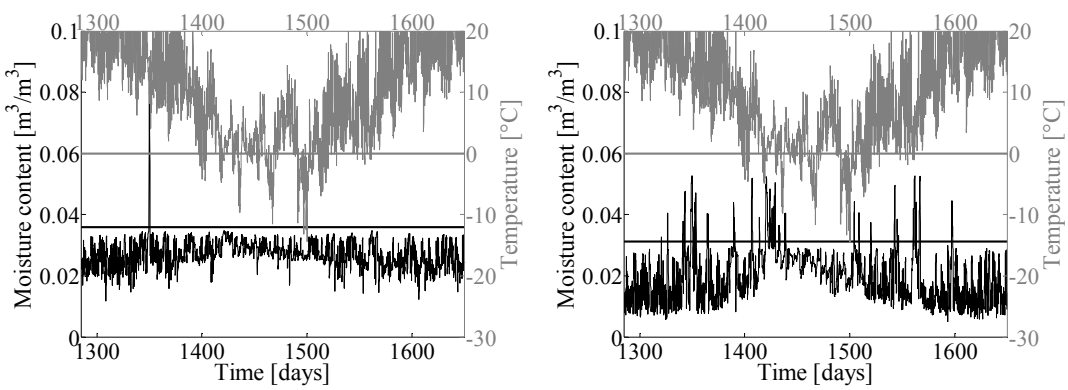

Figure 7: Time behaviour of temperature and moisture content in surface coats on load-bearing structure made of arenaceous marl; $\mathrm{SC}_{1}$ on the left; $\mathrm{SC}_{2}$ on the right.

\section{Discussion}

In this paper, we assumed phase changes of water as the only factor affecting the service life of renovation renders. This is certainly a simplification of the reality on building site but separation of this particular effect from the variety of others can provide valuable information indeed.

All performed computations showed, that freeze-thaw cycles occur in surface coats only. This is given by hydrophobization of both commercial systems of renovation renders which did not allow water to penetrate through surface coat to levelling coat or load-bearing structure.

Taking into account the frost resistance of each coat of renovation render (Table 1), we can predict its service life. The service life of $\mathrm{LC}_{1}+\mathrm{SC}_{1}$ system 

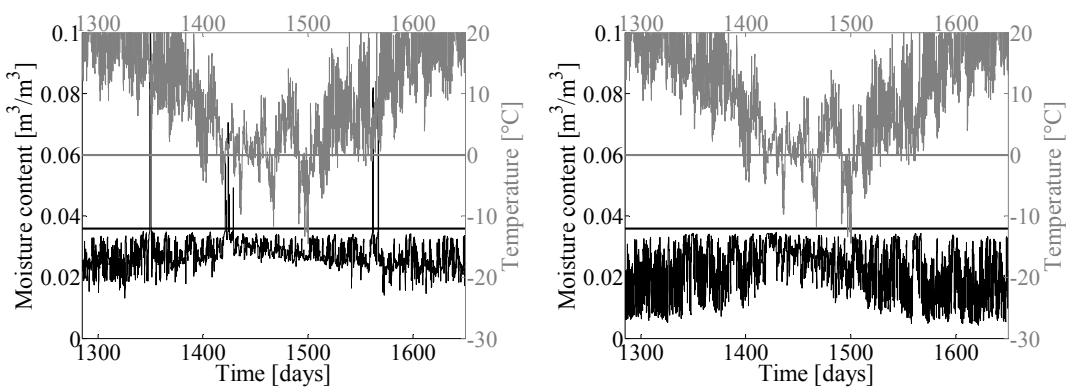

Figure 8: Comparison of computational results with (left) and without (right) involving the effect of hysteresis.

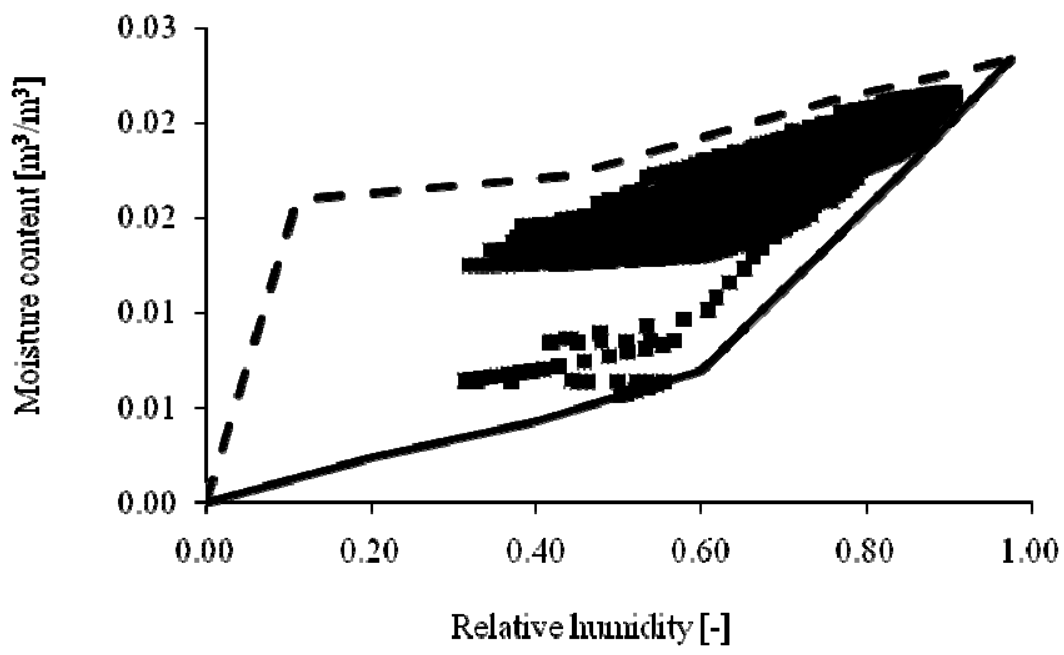

Figure 9: Calculated hysteretic path between adsorption and desorption isotherm of $\mathrm{LC}_{1}$.

was approximately 25 years for combination with brick and over 50 years for combination with sandstone or arenaceous marl. The service life of $\mathrm{LC}_{2}+\mathrm{SC}_{2}$ system was approximately 6 years for combination with brick and 8 years for combination with sandstone or arenaceous marl. This clearly showed that best results were achieved with commercial system $\mathrm{LC}_{1}+\mathrm{SC}_{1}$ regardless of material of load-bearing structure. Although the number of freeze-thaw cycles that occurred in $\mathrm{LC}_{1}+\mathrm{SC}_{1}$ system was much lower than in $\mathrm{LC}_{2}+\mathrm{SC}_{2}$, it is important to note, that $\mathrm{LC}_{1}+\mathrm{SC}_{1}$ lost about $40 \%$ of its tensile strength after only 15 freezethaw cycles, which may shorten its service life.

The other important fact influencing the results of computations was involving the effect of hysteresis of moisture storage and transport parameters. If the effect of hysteresis had not been taken into account, the freeze-thaw cycles would not have occurred at all, regarding all materials. The comparison of both 
computations with and without hysteretic effect taken into account is shown in Fig. 8 .

The example of calculated hysteretic path between adsorption and desorption isotherm of $\mathrm{LC}_{1}$ is shown in Fig. 9.

\section{Conclusions}

The computational results presented in this paper showed, that service life of renovation renders was affected by material of load-bearing structure on which the renders were applied. Among all investigated material combinations, the best results were achieved for load-bearing structure made of arenaceous marl finished by commercial system of renovation renders $\mathrm{LC}_{1}+\mathrm{SC}_{1}$. The service life was estimated to approximately 50 years, which was quite sufficient. However, the durability of renovation renders might lower when considering critical year instead of reference year. It is also important to note that usually the renovation render is salinised much earlier than it gets damaged by freeze-thaw cycles. Therefore the computational model should be extended by involving salt transport, in future works. Other interesting finding was that neglecting the effect of hysteresis may significantly affect the simulation results. In case the hysteresis was neglected the freeze-thaw cycles in the renovation render were never observed.

\section{Acknowledgement}

This research has been supported by the Czech Science Foundation, under grant No. 103/09/0780.

\section{References}

[1] Lu, G., Lu, G.Q., Xiao, Z.M. Mechanical properties of porous materials. Journal of Porous Materials, 6, pp. 359 -368, 1999.

[2] Larbi, J.A. Microscopy applied to the diagnosis of the deterioration of brick masonry. Construction and Building Materials, 18, pp. 299-307, 2004.

[3] Mendes, N., Philippi, P.C. A method for predicting heat and moisture transfer through multilayered walls based on temperature and moisture content gradients. International Journal of Heat and Mass Transfer, 48, pp. 37-51, 2005.

[4] Pel L., Černý R., Pavlík Z. Moisture and Ion Transport. WP5 2-Years Report of the EU 6th Program Project SSPI-CT-2003-501571. TU Eindhoven, Eindhoven, 2006.

[5] Maděra, J., Černý, R. TRANSMAT - A computer simulation tool for modeling coupled heat and moisture transport in building materials. Proceedings of Workshop 2005, CTU: Prague, pp. 470-471, 2005. 
[6] Kruis J., Koudelka T., Krejčí T. Efficient computer implementation of coupled hydro-thermo-mechanical analysis. Mathematics and Computers in Simulation, doi:10.1016/j.matcom.2008.11.010

[7] Künzel, H.M. Simultaneous Heat and Moisture Transport in Building Components, Ph.D. Thesis, IRB Verlag: Stuttgart, pp. 1-135, 1995.

[8] Pedersen, C. R., Combined Heat and Moisture Transfer in Building Constructions, PhD Thesis, Report 214. Thermal Insulation Laboratory, TU Denmark, 1990.

[9] Černý, R., Maděra, J., Kočí, J., Vejmelková, E. Heat and moisture transport in porous materials involving cyclic wetting and drying. Fourteenth International Conference on Computational Methods and Experimental Measurements, Algarve, Portugal. Southampton: WIT PRESS, pp. 3-12, 2009. 